\title{
COVID-19: Metodologias de diagnóstico
}

\author{
COVID-19: Diagnostic methodologies \\ COVID-19: Metodologías de diagnóstico
}

Recebido: 16/04/2021 | Revisado: 23/04/2021 | Aceito: 29/04/2021 | Publicado: 14/05/2021

Agenor Gomes dos Santos Neto ORCID: https://orcid.org/0000-0003-3698-1456 Universidade Tiradentes, Brasil

E-mail: agenor.gomes@souunit.com.br

Alessandro de França Santos ORCID: https://orcid.org/0000-0002-8267-3078 Universidade Tiradentes, Brasil

E-mail: alessandro.franca@souunit.com.br

Jhonata Rodrigues dos Santos ORCID: https://orcid.org/0000-0003-0976-5408 Universidade Tiradentes, Brasil

E-mail: jhonata.rodrigues@ souunit.com.br

Lumar Lucena Alves

ORCID: https://orcid.org/0000-0002-0375-1286 Gerald Champion Regional Medical Center, United States of America E-mail: lalves@gcrmc.org

Anne Caroline Santos Ramos

ORCID: https://orcid.org/0000-0002-0659-7499 Universidade Federal de Sergipe, Brasil

E-mail: annecarolinebiomed@gmail.com

Adilson Allef Moraes Santana

ORCID: https://orcid.org/0000-0003-1678-6899 Universidade Tiradentes, Brasil

E-mail: adilson.allef@ souunit.com.br

Izabella Dayane Dorta dos Santos

ORCID: https://orcid.org/0000-0001-9487-5323 Universidade Tiradentes, Brasil

E-mail: izabella.dayane@ souunit.com.br

Lívia Maria do Amorim Costa Gaspar

ORCID: http://orcid.org/0000-0002-4177-5086 Universidade Tiradentes, Brasil

E-mail: livia.maria@souunit.com.br

\section{Resumo}

Em meados de dezembro de 2019, surgiram os primeiros casos da doença causada pelo novo Coronavírus 2019, o SARS-CoV-2, na cidade de Wuhan (China). A doença causada pelo novo Coronavírus (COVID-19) acomete inicialmente o trato respiratório e seu curso clínico pode acarretar disfunções orgânicas no hospedeiro. Neste ínterim, os exames laboratoriais são ferramentas de diagnóstico de grande importância para a detecção do SARS-CoV-2, confirmação da doença e observação de disfunções sistêmicas. Desta forma, este estudo objetivou revisar as metodologias de diagnóstico do SARS-CoV-2 e alterações nos exames laboratoriais. Trata-se de uma revisão literária realizada entre 01 de janeiro e 31 de maio de 2020 a partir de dados advindos de trabalhos publicados em revistas científicas disponíveis na íntegra. Para tanto, foram utilizadas as bases de dados PubMed, Science Direct e Scielo e os seguintes descritores em inglês: coronavirus, covid-19, sars-cov-2, laboratory medicine, laboratory tests, laboratory findings, RT-PCR, immunochromatography e chemiluminescence. Foram encontrados 2810 artigos científicos relacionados onde apenas 24 foi considerado para o estudo. O SARS-CoV-2 pode ser detectado em amostras respiratórias através de metodologias de diagnóstico laboratorial como o RT-PCR (Real-time Polymerase Chain Reaction) ou através de detecção de anticorpos através dos testes imunocromatográficos, imunosorventes e quimioiluminescentes. Además, podem ser observadas alterações hematológicas relacionadas ao leucograma, coagulação, marcadores hepáticos e renais bem como marcadores inflamatórios. Em suma, as ferramentas de diagnóstico têm sido cruciais para o acompanhamento do paciente com sintomas da COVID, servindo de apoio aos clínicos na tomada de decisões.

Palavras-chave: Coronavírus; Síndrome Respiratória aguda grave; Sorologia; Biologia molecular; Revisão da literatura. 


\begin{abstract}
The first cases of COVID-19 were registered in the city of Wuhan (China) in December 2019. The disease caused by the new Coronavirus (SARS-CoV-2) initially affects the respiratory tract and its clinical effects can lead to organic dysfunction in the host. In this context, laboratory tests are diagnostic tools of great relevance for the detection of SARS-CoV-2, confirmation of the disease and evaluation of systemic dysfunctions caused by the virus. Thus, this study aimed to conduct an up-to-date about COVID-19 and discuss the diagnostic methodologies of SARS-CoV-2 and its effects in laboratory tests. The present study was performed between January 1st and May 31st, 2020 based on data from works published in scientific journals available in full. For that, PubMed, Science Direct and Scielo databases was used besides the following descriptors in English: coronavirus, covid-19, sars-cov-2, laboratory medicine, laboratory tests, laboratory findings, RT-PCR, immunochromatography and chemiluminescence. In total, 2810 related scientific articles were found, of which only 24 were considered relevant for the study. SARS-CoV-2 can be detected in respiratory samples using laboratory diagnostic methodologies such as RT-PCR (Real-time Polymerase Chain Reaction) or by detecting antibodies through immunochromatographic, immunosorbent and chemiluminescent tests. In addition, hematological changes related to the leukogram, changes in the coagulation panel, changes in liver and kidney markers as well as inflammatory markers can be observed. Finally, the diagnostic tools have been crucial for monitoring the patient with symptoms of COVID, providing support to clinicians in decision-making.
\end{abstract}

Keywords: Coronavirus; severe acute respiratory syndrome; Serology; Molecular biology; Literature review.

\title{
Resumen
}

A mediados de diciembre de 2019 aparecieron en la ciudad de Wuhan (China) los primeros casos de la enfermedad provocada por el nuevo Coronavirus 2019, SARS-CoV-2. La enfermedad provocada por el nuevo Coronavirus (COVID-19) afecta inicialmente al tracto respiratorio y su curso clínico puede provocar disfunciones orgánicas en el hospedador. Mientras tanto, las pruebas de laboratorio son herramientas de diagnóstico de gran importancia para la detección del SARS-CoV-2, la confirmación de la enfermedad y la observación de disfunciones sistémicas. Por lo tanto, este estudio tuvo como objetivo revisar las metodologías de diagnóstico del SARS-CoV-2 y los cambios en las pruebas de laboratorio. Se trata de una revisión literaria realizada entre el 1 de enero y el 31 de mayo de 2020 en base a datos de trabajos publicados en revistas científicas disponibles en su totalidad. Para ello se utilizaron las bases de datos PubMed, Science Direct y Scielo y los siguientes descriptores en inglés: coronavirus, covid-19, sars-cov-2, laboratory medicine, laboratory tests, laboratory findings, RT-PCR, immunochromatography e chemiluminescence. Se encontraron 2810 artículos científicos relacionados donde solo 24 fueron considerados para el estudio. El SARSCoV-2 se puede detectar en muestras respiratorias utilizando metodologías de diagnóstico de laboratorio como RTPCR (Reacción en cadena de la polimerasa en tiempo real) o mediante la detección de anticuerpos mediante pruebas inmunocromatográficas, inmunoabsorbentes y quimioluminiscentes. Además, se pueden observar cambios hematológicos relacionados con leucograma, coagulación, marcadores hepáticos y renales así como marcadores inflamatorios. En definitiva, las herramientas de diagnóstico han sido cruciales para el seguimiento del paciente con síntomas de COVID, brindando apoyo a los médicos en la toma de decisiones.

Palabras clave: Coronavirus; Síndrome respiratorio agudo severo; Serología; Biología molecular; Revisión de la literatura.

\section{Introdução}

Em meados de dezembro de 2019, surgiram surtos de pneumonia na cidade de Wuhan, China, que acabaram despertando a atenção de todo o mundo (Wu et al., 2020; Zhou et al., 2020) . A partir de investigações preliminares foi constatado que a patologia era causada por um vírus, que foi previamente designado de novo Coronavírus 2019 (2019 n-CoV). Também foi notado que o microrganismo se tratava de uma nova linhagem de Coronavírus. Os primeiros indivíduos diagnosticados com os sintomas referentes ao vírus em questão, tiveram contato com animais comercializados em mercados de frutos do mar. Logo, foi observado vários surtos em locais próximos de Wuhan (Huang et al., 2020; Qun Li et al., 2020; Zhu et al., 2020).

$\mathrm{O}$ vírus atingiu países próximos e, mais tarde, chegou a todos os continentes. A rápida disseminação do vírus, consequentemente, acabou por resultar no aumento de casos e mortes relacionados a nova patologia emergente e aos poucos um estado de atenção foi se instalando por todos os continentes (Qun Li et al., 2020). Como forma de alertar a sociedade sobre essa situação preocupante, a Organização Mundial da Saúde (OMS) logo o definiu como pandemia e assim, marco inicial para uma emergência de saúde pública (Sui-Lee et al., 2020). 
O microrganismo pertence a um grupo de vírus denominado de Coronavírus, que possuem material genético constituído de RNA e envolvidos por um envelope, do qual encontra-se proteínas em sua superfície (Tortora et al., 2016). Essas proteínas, especialmente as proteínas spikes, conferem a aparência de uma coroa. A palavra Coroa vem do latim Corona, e por conta dessa característica os vírus recebeu tal denominação. Além de caracterizar o grupo dos Coronavírus, essas proteínas estariam relacionadas com a origem do recente agente etiológico (Gallagher \& Buchmeier, 2001; Hoffmann et al., 2020)

A origem do novo Coronavírus ainda não foi confirmada. Até então sabe-se sobre sua presença em animais e que podem ser transmitidos aos seres humanos, fato esse nomeado de transbordamento ou Spillover (Decaro \& Lorusso, 2020). Além disso, as proteínas spike seriam um fator importante para a sua adaptação e, consequentemente, para a sua capacidade de infectar as células humanas (Andersen et al., 2020).

O quadro patológico causado pelo novo Coronavírus foi definido pela Organização Mundial da Saúde como COVID19 (doença causada pelo novo Coronavírus) (World Health Organization, 2020). Enquanto, o vírus recebeu uma denominação oficial pelo Comitê Internacional de Taxonomia de Vírus (ICTV) de SARS-CoV-2 (Severe acute respiratory syndrome coronavirus 2), caracterizando o agente etiológico da doença. Portanto, o COVID-19 é o nome da doença infecciosa causada pelo novo Coronavírus, o SARS-CoV-2 (Gorbalenya et al., 2020).

O SARS-CoV-2 pode ser detectado em amostras respiratórias através de metodologias de diagnóstico laboratorial. Os testes rápidos imunocromatográficos, apesar de não serem considerados sensíveis o suficiente para o diagnóstico confirmatório da doença, auxiliam na identificação de anticorpos ou antígenos (Shen et al., 2020). O método considerado padrão ouro é a RT-PCR (Reverse Transcriptase Polymerase Chain Reaction), visto que essa técnica identifica o material genético do microrganismo. Outras informações, tais como as alterações laboratoriais podem auxiliar no monitoramento do paciente, no que diz respeito a evolução da doença (Corman et al., 2020; W. Wang et al., 2020).

Estudos demonstram que apesar da COVID-19 ser uma doença que acomete o trato respiratório, seu curso clínico pode acarretar disfunções orgânicas no hospedeiro. Estas podem ser observadas por meio de alterações hematológicas, hemostáticas e bioquímicas (Colantuoni et al., 2020; Guan et al., 2020; Lippi \& Plebani, 2020; L. Wu et al., 2020; Zhang et al., 2020).

Devido a importância dos exames laboratoriais no diagnóstico do paciente com a COVID-19, bem como para o monitoramento da doença, esta revisão traz uma sumarização e discussão acerca das metodologias de diagnóstico do SARSCoV-2 e anormalidades nos exames laboratoriais.

\section{Metodologia}

Trata-se de uma revisão literária narrativa realizada entre janeiro de 2020 a março de 2021 com o objetivo primário apresentar as metodologias diagnósticas para a detecção do vírus SARS-CoV-2 em amostras clínicas, bem como descrever os achados laboratoriais encontrados em pacientes diagnosticados com o vírus.

Neste estudo, os critérios de inclusão estabelecidos foram artigos científicos publicados na íntegra e relacionados com a descrição de novas metodologias, aprimoramento de técnicas, validação de métodos, além de alterações hematológicas e bioquímicas decorrentes das alterações fisiopatológicas ocasionadas pelo vírus. Artigos de revisão e publicados fora do período estabelecidos não foram incluídos neste estudo.

\subsection{Estratégia de busca}

Foram utilizados trabalhos publicados no período entre 01 de janeiro e 31 de dezembro de 2020 nas bases de dados PubMed, Science Direct e Scielo. Foram utilizados os seguintes descritores em inglês: coronavirus, COVID-19, SARS-CoV- 
2, laboratory medicine, laboratory tests, laboratory findings, RT-PCR, immunochromatography e chemiluminescence, utilizando também os operadores Booleanos "Or" e "And" para auxiliar a busca.

\subsection{Processo de seleção dos estudos}

Inicialmente os estudos identificados pelas buscas nas bases de dados foram tabulados no Microsoft Office Excel ${ }^{\oplus}$. Os critérios de elegibilidade obedeceram a três fases de seleção: a primeira com a leitura do título e objetivo, a segunda seguiu com a leitura do resumo e a terceira com a leitura completa do artigo. Referências repetidas foram identificadas e removidas. Os artigos selecionados foram lidos e interpretados pelos autores e os dados relevantes foram implementados neste trabalho. Os resultados foram apresentados em diagnóstico laboratorial do SARS-CoV-2 e alterações laboratoriais.

\section{Resultados e Discussão}

\subsection{Estudos selecionados}

O presente estudo identificou inicialmente na primeira fase um total de 2810 trabalhos, dos quais 2029 foram encontrados na PubMed, 743 na Scielo e 38 na Science Direct. Na segunda fase de seleção foram incluídos 210 estudos, onde apenas 24 foram considerados para esta revisão (Quadro 1). 
Quadro 1. Síntese dos estudos incluídos apresentando os principais parâmetros laboratoriais avaliados no diagnóstico, manejo e prognóstico da infecção por SARS-CoV-2.

\begin{tabular}{|c|c|c|c|c|c|c|}
\hline $\begin{array}{l}\text { Autor, } \\
\text { data }\end{array}$ & $\begin{array}{c}\text { Parâmetros } \\
\text { avaliados }\end{array}$ & $\begin{array}{l}\text { Técnica } \\
\text { Diagnóstica da } \\
\text { Infecção }\end{array}$ & $\begin{array}{c}\text { Alterações } \\
\text { hematológicas }\end{array}$ & Alterações Bioquímicas & $\begin{array}{l}\text { Alterações } \\
\text { Hemostáticas }\end{array}$ & Desfecho \\
\hline Ling et al., 2020 & BIOMOL & RT-PCR & NR & NR & NR & $\begin{array}{l}\text { Observação da depuração do RNA viral em amostras de fezes, } \\
\text { urina e soro. A depuração do RNA viral foi mais atrasada nas } \\
\text { fezes, em comparação com os swabs orofaríngeos. }\end{array}$ \\
\hline K. Liu et al., 2020 & BIOMOL & RT-PCR & $\begin{array}{c}\mathrm{N} \text { ou } \downarrow \\
\text { leucócitos } \\
\text { Linfocitopenia }\end{array}$ & NR & NR & $\begin{array}{l}\text { Presença de febre como primeiro sintoma e manifestações } \\
\text { típicas de pneumonia viral. Pior prognóstico com o aumento da } \\
\text { idade e presença de comorbidades }\end{array}$ \\
\hline X. Wang et al., 2020 & BIOMOL & RT-PCR & NR & NR & NR & $\begin{array}{c}\text { Swab nasofaríngeo é o mais adequado em comparação ao } \\
\text { orofaríngeo, com maior taxa de positividade nas amostras de } \\
\text { nasofaringe. }\end{array}$ \\
\hline Yu et al., 2020 & BIOMOL & ddPCR e RT-PCR & NR & NR & NR & $\begin{array}{l}\text { O monitoramento quantitativo da carga viral em amostras do } \\
\text { trato respiratório inferior auxilia na avaliação da progressão da } \\
\text { doença, principalmente em casos de baixa carga viral. ddPCR } \\
\text { pode ser mais sensível que ddPCR na identificação do SARS- } \\
\text { CoV-2. }\end{array}$ \\
\hline R. Liu, et al., 2020 & BIOMOL & qRT-PCR e NAT & NR & NR & NR & $\begin{array}{c}\text { Uso do NAT como possibilidade diagnóstica do SARS-CoV-2 } \\
\text { em amostra de lavagem broncolaveolar, mas pouco útil em } \\
\text { amostras de swab nasofaríngeo. }\end{array}$ \\
\hline Shen et al., 2020 & IMUNO & Imunocromatografia & NR & NR & NR & $\begin{array}{l}\text { A Imunocromatografia teve sensibilidade de } 71,1 \% \text { e } \\
\text { especificidade de } 96,2 \% \text { na população estudada, demonstrando } \\
\text { seu potencial para diagnóstico rápido e útil para COVID- } 19 \text {. }\end{array}$ \\
\hline Pan et al., 2020 & IMUNO & Imunocromatografia & NR & NR & NR & $\begin{array}{c}\text { A sensibilidade do ensaio com detecção de IgM e IgG em casos } \\
\text { confirmados foi de } 11,1 \%, 92,9 \% \text { e } 96,8 \% \text { no estágio inicial ( } 1 \\
\text { a } 7 \text { dias após o início dos sintomas), estágio intermediário ( } 8 \\
\text { a14 dias após o início dos sintomas) e estágio tardio (mais de } \\
15 \text { dias), respectivamente. }\end{array}$ \\
\hline Demey et al., 2020 & IMUNO & Imunocromatografia & NR & NR & NR & $\begin{array}{l}\text { Demonstra heterogeneidade na detecção de anticorpos após o } \\
\text { início dos sintomas e tempo médio de detecção de anticorpos } \\
\text { entre } 8 \text { e } 10 \text { dias, de acordo com os fabricantes. Todos os testes } \\
\text { apresentaram sensibilidade de } 60 \text { a } 80 \% \text { no } 10^{\circ} \text { dia e } 100 \% \text { no } \\
15^{\circ} \text { dia após início dos sintomas. }\end{array}$ \\
\hline Imai et al., 2020 & IMUNO & Imunocromatografia & NR & NR & NR & $\begin{array}{l}\text { Apenas o resultado da imunocromatografia não é suficiente } \\
\text { para diagnóstico de COVID-19, podendo ser combinado a TC } \\
\text { de tórax, caso a qRT-PCR esteja indisponível. }\end{array}$ \\
\hline Ai et al., 2020 & $\begin{array}{l}\text { BIOMOL } \\
\text { IMG }\end{array}$ & RT-PCR e TC & NR & NR & NR & $\begin{array}{l}\text { Correlação da melhora de pacientes por meio de exames de } \\
\text { imagem com a diminuição da carga viral. }\end{array}$ \\
\hline
\end{tabular}




\begin{tabular}{|c|c|c|c|c|c|c|}
\hline C. Huang et al., 2020 & HEMATO & NR & $\begin{array}{c}\text { Plaquetopenia } \\
\text { Eosinopenia }\end{array}$ & $\uparrow \mathrm{AST}$ & $\begin{array}{l}\text { Alterações no } \\
\text { Tempo de } \\
\text { Protrombina e } \\
\text { dímero D } \\
\end{array}$ & $\begin{array}{c}\text { Correlação dos achados bioquímicos e hematológicos com o } \\
\text { agravamento da doença. }\end{array}$ \\
\hline Lippi et al., 2020a & HEMATO & NR & Plaquetopenia & NR & Plaquetopenia & $\begin{array}{c}\text { A baixa contagem de plaquetas está associada a maior risco de } \\
\text { doença grave e mortalidade em pacientes com COVID-19, } \\
\text { servindo como indicador clínico de agravamento da doença } \\
\text { durante a hospitalização. }\end{array}$ \\
\hline Paoli et al., 2020 & BIOMOL & qRT-PCR & NR & NR & NR & $\begin{array}{l}\text { A pesquisa de RNA SARS-CoV-2 em amostras de sêmen e } \\
\text { urina foi negativa, possivelmente pela cinética de depuração } \\
\text { viral nessas matrizes, não podendo confirmar melhora clínica. }\end{array}$ \\
\hline Peng et al., 2020 & BIOMOL & qRT-PCR & NR & NR & NR & $\begin{array}{l}\text { Testes em diferentes tipos de biológicas podem ter uma } \\
\text { utilidade diante do monitoramento de alterações, progressão da } \\
\text { doença e estabelecimento do prognóstico. }\end{array}$ \\
\hline G. Zhang et al., 2020 & $\begin{array}{l}\text { BIOMOL } \\
\text { HEMATO } \\
\text { BIOQ }\end{array}$ & qRT-PCR & $\begin{array}{l}\text { Leucocitose } \\
\text { Linfocitopenia } \\
\text { Neutrofilia }\end{array}$ & $\begin{array}{l}\uparrow \mathrm{PCR}, \mathrm{AST}, \mathrm{ALT}, \mathrm{LDH}, \mathrm{CK}, \\
\text { CREA } \\
\downarrow \mathrm{PT}\end{array}$ & $\begin{array}{l}\text { Nível mais alto de } \\
\text { dímero D em } \\
\text { pacientes } \\
\text { hospitalizados }\end{array}$ & $\begin{array}{l}\text { Envolvimento de marcadores bioquímicos, de hemostasia e } \\
\text { hematológicos, em pacientes hospitalizados com COVID-19. A } \\
\text { linfopenia foi provavelmente causada pela translocação de } \\
\text { linfócitos do sangue periférico para os pulmões. O dímero D e } \\
\text { marcadores de função hepática relacionam-se a casos graves de } \\
\text { pneumonia por SARS-CoV-2. Elevação de AST, ALT e CK } \\
\text { possuem correlação com os casos mais graves. A diminuição de } \\
\text { PT refletiu um maior consumo de nutrição. }\end{array}$ \\
\hline L. Chen et al., 2020 & HEMATOBIOQ & NR & Linfocitopenia & $\begin{array}{c}\uparrow \text { PCR, LDH } \\
\text { N PCT, AST, ALT, BILTF } \\
\quad \downarrow \text { ALB } \\
\uparrow \text { expressão de IL-2R e IL-6 }\end{array}$ & NR & $\begin{array}{l}\text { Além das alterações hematológicas, houve elevação de } \\
\text { citocinas pró-inflamatórias, com associação ao aumento da } \\
\text { gravidade e pior prognóstico. }\end{array}$ \\
\hline X. Chen et al., 2020 & $\begin{array}{l}\text { HEMATO } \\
\text { BIOQ }\end{array}$ & Hemograma & $\begin{array}{l}\mathrm{N} \text { ou } \downarrow \\
\text { leucócitos e } \\
\text { neutrófilos, } \\
\text { Linfocitose }\end{array}$ & $\begin{array}{c}\downarrow \text { PCT } \\
\text { N ou } \downarrow \text { BILTF } \\
\uparrow \text { AST, ALT, LDH, CK, UREA } \\
\text { S/A PCR }\end{array}$ & NR & $\begin{array}{l}\text { Apresentação frequente de alterações no hemograma, UREA e } \\
\text { CK nos pacientes COVID-19 positivos que nos pacientes } \\
\text { controle. Os níveis aumentados de PCT diferenciaram os } \\
\text { pacientes COVID-19 dos pacientes controle. }\end{array}$ \\
\hline Hou et al., 2020 & $\begin{array}{l}\text { HEMATO } \\
\text { BIOQ }\end{array}$ & $\begin{array}{c}\text { Ensaio } \\
\text { Imunométrico } \\
\text { Quimioluminescente }\end{array}$ & $\begin{array}{l}\text { Leucocitose } \\
\text { Neutrofilia } \\
\text { Linfopenia }\end{array}$ & $\begin{array}{c}\uparrow \text { PCR, PCT, IL-2R, IL-6, IL-8, } \\
\text { IL-10 e TNF- } \alpha\end{array}$ & NR & $\begin{array}{l}\text { Aumento de citocinas em pacientes graves e críticos, assim } \\
\text { como a } \\
\text { correlação IL-2R / linfócitos. Em pacientes recuperados, os } \\
\text { perfis de citocinas e IL-2R/linfócitos foram significativamente } \\
\text { reduzidos. O IL-2R / linfócito foi um biomarcador proeminente } \\
\text { para a identificação precoce de COVID-19 grave e predição da } \\
\text { progressão clínica da doença. }\end{array}$ \\
\hline Q. Huang et al., 2020 & $\begin{array}{l}\text { HEMATO } \\
\text { BIOMOL }\end{array}$ & qRT-PCR & $\begin{array}{l}\text { Leucopenia } \\
\text { Eosinopenia }\end{array}$ & $\begin{array}{c}\uparrow \mathrm{ALT}, \mathrm{AST}, \mathrm{LDH}, \mathrm{PCR}, \mathrm{CK} \\
\downarrow \\
\downarrow \mathrm{PT}, \mathrm{ALB}, \mathrm{URI}\end{array}$ & NR & $\begin{array}{l}\text { Dentre os } 54 \text { pacientes ( } 51 \text { com COVID-19 do tipo comum, três } \\
\text { com o tipo grave), foi relatado que } 14 \text { pacientes apresentaram, } \\
\text { leucopenia, eosinopenia e diminuição da contagem de } \\
\text { plaquetas. Em contrapartida, os pacientes com COVID-19 em } \\
\text { estado grave, apresentaram piores resultados, como níveis }\end{array}$ \\
\hline
\end{tabular}




\begin{tabular}{|c|c|c|c|c|c|c|}
\hline & & & & & & $\begin{array}{c}\text { anormais de biomarcadores inflamatórios, CK, CK-MB, LDH e } \\
\text { hs-CRP. }\end{array}$ \\
\hline Qilin. Li et al., 2020 & $\begin{array}{l}\text { BIOMOL } \\
\text { HEMATO }\end{array}$ & RT-PCR & $\begin{array}{l}\mathrm{N} \text { ou } \downarrow \\
\text { leucócitos } \\
\text { Linfopenia } \\
\text { Eosinopenia }\end{array}$ & $\uparrow$ PCR-us & NR & $\begin{array}{c}\text { Na avaliação da capacidade preditiva de biomarcadores, a } \\
\text { relação Eosinopenia/PCRus foi efetiva para triagem dos casos } \\
\text { suspeitos quando comparados a pacientes febris por outras } \\
\text { causas. Este achado seria particularmente útil para projetar } \\
\text { estratégias de triagem em uma região epidêmica com } \\
\text { ocorrência de outras doenças respiratórias, enquanto recursos } \\
\text { médicos limitados para testes de ácido nucléico e exame } \\
\text { radiográfico. }\end{array}$ \\
\hline Padoan et al., 2020 & IMUNO & $\begin{array}{l}\text { Ensaios MAGLUMI } \\
\text { TM } 2000 \text { Plus 2019- } \\
\text { nCov IgM e IgG }\end{array}$ & NR & NR & NR & $\begin{array}{l}\text { Foi demonstrado no estudo a validade do ensaio MAGLUMI } \\
2000 \text { Plus CLIA para medição de IgM e IgG específicos em } \\
\text { soros de pacientes COVID-19 e para a obtenção de dados sobre } \\
\text { a cinética de ambos os anticorpos. }\end{array}$ \\
\hline Jin et al., 2020 & IMUNO & CLIA & NR & NR & NR & $\begin{array}{c}\text { Foi observado que o teste sorológico viral é um meio eficaz de } \\
\text { diagnóstico de infecção por SARS-CoV-2 devido à alta a } \\
\text { sensibilidade e especificidade, respectivamente, para detecção } \\
\text { de IgM }(48,1 \% / 100 \%) \text { e IgG }(88,9 \% / 90,9 \%) \text {. }\end{array}$ \\
\hline Cai et al., 2020 & IMUNO & $\begin{array}{l}\text { Imunoensaio } \\
\text { luminescente } \\
\text { baseado em } \\
\text { peptídeo sintético }\end{array}$ & NR & NR & NR & $\begin{array}{c}\text { A IgG foi detectada em } 71,4 \%(197 / 276) \text { de todos os soros, } \\
\text { maior do que a taxa de detecção de IgM }(57,2 \%, 158 / 276) \text {. } \\
\text { Uma combinação dos dois anticorpos aumentou a taxa de } \\
\text { detecção para } 81,5 \%(225 / 276) .\end{array}$ \\
\hline Lippi et al., 2020b & IMUNO & $\begin{array}{l}\text { MAGLUMI 2019- } \\
\text { nCoV IgG e IgM }\end{array}$ & NR & NR & NR & $\begin{array}{l}\text { Presença de concordância (90\%) entre dois imunoensaios } \\
\text { comerciais (MAGLUMI 2019-nCoV IgM e IgG e do } \\
\text { Euroimmun Anti-SARS-CoV-2 IgA e IgG) na detecção de } \\
\text { anticorpos anti-SARS-CoV-2, especialmente para IgG e para } \\
\text { ambas as imunoglobulinas combinadas. }\end{array}$ \\
\hline
\end{tabular}

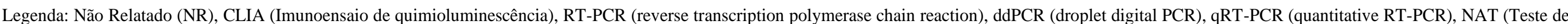

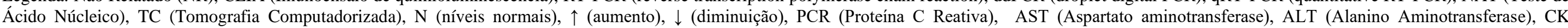

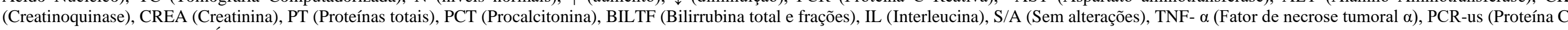

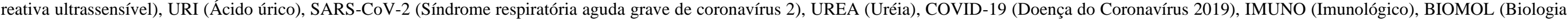
molecular), HEMATO (Hematológico), BIOQ (Bioquímico), IMG (Imagem).

Fonte: Autores (2021). 


\subsection{Diagnóstico laboratorial do SARS-CoV-2}

\subsubsection{RT-PCR (Reverse Transcription Polymerase Chain Reaction)}

O RT-PCR é uma técnica de transcrição reversa seguida de reação em cadeia da polimerase em tempo real, do inglês, Reverse Transcription Polymerase Chain Reaction. Esta tem sido relatada como principal método o diagnóstico da COVID-19, pois detecta o material genético do SARS-CoV-2 em amostras do trato respiratório com alta sensibilidade (Chan et al., 2020). Essa técnica tem como principais características sua especificidade, precisão e depende de variáveis pré-analíticas e analíticas. Esta técnica é capaz de detectar o RNA viral em material coletado no período de 4 a 6 dias após a infecção, sendo necessário cuidados com a transporte e manipulação da amostra (Brasil, 2020; Kim et al., 2020; Younes et al., 2020). Por isso, uma das principais exigências da RT-PCR é a alta carga viral para evitar falsos resultados (Y. Li et al., 2020). Vale ressaltar que o SARS-CoV-2 é um vírus de RNA, portanto esse método é realizado com o emprego da transcriptase reversa antes da implementação da qPCR (Quantitative Real-Time Polymerase Chain Reaction), pois essa enzima é capaz de gerar uma fita de DNA complementar e assim permite que a qPCR o detecte (Yu et al., 2020).

Contudo, muitos pesquisadores que utilizaram a RT-PCR, usaram diferentes métodos e sistemas com diferenças entre o modo de execução, seguindo as instruções do fabricante para a realização da RT-PCR ou fazendo adaptações no método (Jin et al., 2020; Ling et al., 2020; K. Liu et al., 2020; X. Wang, et al., 2020; Yu et al., 2020). Para a detecção do RNA viral, pesquisadores se basearam nos genes ORF1ab e da proteína nucleocapsídica (NP), para a confirmar a presença do SARS-CoV2 (R. Liu et al., 2020; X. Wang, Tan, Wang, Liu, Lu, \& Cheng, 2020; Yu et al., 2020). Em sua pesquisa, R. Liu et al. (2020) seguiu as instruções do fabricante Shangai Huirui Biotechnology Co., Ltd., e considerou as seguintes condições para a amplificação como favoráveis para a realização da RT-PCR: $50^{\circ} \mathrm{C}$ por 15 minutos, $95^{\circ} \mathrm{C}$ por 3 minutos, seguido de 45 ciclos de $95^{\circ} \mathrm{C}$ por 15 segundos e $60^{\circ} \mathrm{C}$ por 30 segundos. Assim como o estudo anterior, Yu et al. (2020), também seguiram especificações do fabricante, Shangai BioGerm Medical Technology Co Ltd, China, para a realização da qRT-PCR. No entanto, além da q RT-PCR, o estudo utilizou outra metodologia de detecção do RNA viral, o ddPCR (Droplet Digital Polymerase Chain Reaction). O ddPCR, foi realizado através de um kit de detecção de PCR digital para COVID-19 (Targeting, Beijing, China), com o uso do sistema de PCR digital TargetingOne, licenciado pela China Food and Drug Administration (CFDA).

Por outro lado, Ling et al. (2020) utilizaram um kit de extração com a adição de um método de cordão magnético automatizado (magnetic-bead method) (Master Biotechnology, China) e a RT-PCR por fluorescência dupla (dual fluorescence PCR) (Applied Biosystems 2516582407500 Real-Time PCR Systems, Foster City, CA, USA), seguindo as instruções do fabricante. Outro estudo realizou o ensaio de RT-PCR através de um sistema automatizado o Tianlong PANA9600, utilizando as seguintes condições: $50^{\circ} \mathrm{C}$ por 15 minutos, $95^{\circ} \mathrm{C}$ por 15 minutos, 45 ciclos de $94^{\circ} \mathrm{C}$ por 15 segundos, $55^{\circ} \mathrm{C}$ para coleta de fluorescência (Wang, Tan, Wang, Liu, Lu, \& Cheng, 2020).

As condições favoráveis para a realização da RT-PCR, não foram as únicas diferenças entre as instruções de cada fabricante, já que o valor do ciclo limiar (Cycle Threshold - CT) também foi diferente para cada fabricante. O CT ou valor limiar, corresponde ao limite de ciclos de RT-PCR necessários para atingir o nível de fluorescência. É importante enfatizar que a menor quantidade de ciclos de RT-PCR corresponde a uma amostra com maior carga viral. Portanto, cada fabricante determina um valor do CT considerando seus sistemas e especificações. Foi notado que cada pesquisa se adequou as instruções dos fabricantes, por isso pode ser observado diferentes valores do CT (Wishaupt et al., 2020). Na pesquisa de X. Wang et al. (2020), o valor limiar foi de 40 para ambos os genes, onde os valores menores que 40 eram positivos e os valores que ultrapassavam eram considerados negativos. Outro estudo utilizou o valor CT de 38 para a testagem positiva, sendo que os valores maiores seriam negativos (Yu et al., 2020). Liu et al. (2020) (Liu et al., 2020), seguiram as instruções do fabricante que determinou o valor CT abaixo de 37 para testagem positiva, e valores acima de 40 para testagem negativa. 
Em uma pesquisa que objetivou correlacionar a carga viral na detecção do RNA viral através de métodos de biologia molecular, compararam a avaliação de dois métodos de detecção, a RT-PCR e a ddPCR (Yu et al., 2020). A consistência dos resultados em 95 amostras positivas e o valor de CT, foram pontos fundamentais para a avaliação da RT-PCR e da ddPCR. Os valores de CT foram importantes para a avaliação da sensibilidade dos dois métodos, sobretudo no que diz respeito a carga viral presente nas amostras analisadas. O ddPCR demonstrou maior sensibilidade a baixa carga viral, em contrapartida, a RTPCR pode não refletir sensibilidade quando a carga viral for baixa.

Para detectar o SARS-CoV-2 é recomendado a utilização de amostras do trato respiratório, visto que o vírus apresenta afinidade com células do sistema respiratório. No estudo de Wang et al. (2020) (X. Wang, Tan, Wang, Liu, Lu, \& Cheng, 2020), foi comparado a análise de duas amostras respiratórias: o swab orofaríngeo e o swab nasofaríngeo. Foi observado que o swab nasofaríngeo demonstrava a maior taxa positiva já que teria maior carga do vírus, sobretudo nos pacientes internados, sendo mais recomendados para a detecção do RNA viral, já que o swabs orofaríngeo parece estar mais propenso a resultados falso-negativos (Wang, Tan, Wang, Liu, Lu, \& Cheng, 2020).

A pesquisa de Lin et al. (2020), realizou a comparação entre dois tipos de amostras para a detecção através da RTPCR, o swab orofaríngeo e o escarro. Dos 53 pacientes inclusos no estudo, 23 (44,2\%) casos foram positivos a partir da análise do swab orofaríngeo, enquanto 55,8\% dos casos foram negativos para o SARS-CoV-2. Já a análise do escarro obteve 76,9\% de positividade, sendo $23,1 \%$ para os casos negativos. Contudo, é evidente a alta taxa de positividade da análise do escarro, quando comparado com os swabs orofaríngeos. Ressalta-se que a utilização do escarro pode ter limitações, visto que nem todos os pacientes com a COVID-19 produzem escarro (Lin et al., 2020).

O SARS-CoV-2, além de ser detectado em amostras do trato respiratório (lavado broco alveolar, escarro, swab de nasofaringe e orofaringe), também foi detectado em amostras de fezes e sangue (W. Wang et al., 2020; Y. Wu et al., 2020). Na urina, o SARS-CoV-2 foi detectado nos estudos de Paoli et al. (2020) e Peng et al. (2020). A detecção do vírus nestes sítios sugere que o vírus consegue alcançar diversos tecidos do hospedeiro.

\subsubsection{Imunocromatografia}

Considerando o tempo de realização, como também os custos financeiros da metodologia para detecção de ácidos nucleicos (Corman et al., 2020), viu-se a necessidade de produzir e avaliar a sensibilidade e a especificidade dos testes rápidos com a intenção de obter um diagnóstico em um curto espaço de tempo e que não precise ter a utilização de equipamentos mais sofisticados para realização do exame laboratorial para identificar a doença causada pelo SARS-CoV-2 (Shen et al., 2020)

$\mathrm{O}$ teste rápido utiliza o método imunocromatográfico que consiste na busca da reação de anticorpos imunoglobulina M (IgM) ou imunoglobulina G (IgG) no sangue (Shen et al., 2020). Os anticorpos são produzidos e secretados pelos linfócitos $\mathrm{B}$ do sistema imunológico quando há exposição do organismo humano ao patógeno. A IgM é geralmente o primeiro anticorpo a ser secretado por possuir uma estrutura pentâmera que elimina patógenos antes da produção da IgG, sendo essa última utilizada como anticorpo de memória, assim realizando um ataque específico, evitando o organismo adoecer devido a exposição do mesmo patógeno (Pan et al., 2020).

Segundo Demey et al. (2020) um teste rápido é um dispositivo composto por um local de adição da amostra junto a um tampão de diluição e a janela de leitura, que consiste em uma tira de nitrocelulose onde ocorrerá a reação dos anticorpos junto a amostra biológica do paciente. Para realização do teste, segundo Pan et al.. (2020) é necessário seguir as instruções do kit de cada fabricante, porém, geralmente utilizam de $10 \mathrm{uL}$ a $20 \mathrm{uL}$ de sangue ou soro sanguíneo e em torno de $100 \mathrm{uL}$ da solução de diluição e aguardar de 10 a 15 minutos após a adição do diluente para obter o resultado do teste.

A presença apenas da linha de controle é interpretada como resultado negativo. Já a presença da linha de controle juntamente com a linha de anticorpo IgM (anticorpo de fase aguda da infecção) ou IgG (anticorpo de memória imunológica da 
infecção) indicam um resultado positivo para o teste. A ausência da linha de controle, independente se alguma linha de anticorpo apareceu, é interpretada como teste inválido, ou seja, o mesmo deve ser descartado já que indica um resultado inconclusivo (Pan et al., 2020).

Em relação às vantagens do método de imunocromatografia estão o rápido resultado do teste, a economia de capital, facilidade de execução sem demandar de um profissional qualificado para interpretação (Shen et al., 2020). A sensibilidade do teste rápido também foi levantada como excelente nos estudos de Demey et al. (2020) e Pan et al. (2020), ambos relatam que a sensibilidade e a especificidade dos testes rápidos em buscam de anticorpos IgM e $\operatorname{IgG}$ aumentam com o passar do $6^{\circ}$ e $7^{\circ}$ dia após o primeiro dia de sintoma, tendo uma sensibilidade maior após o $15^{\circ}$ dia, assim liberando um resultado qualitativo. Em contrapartida, Imai et al. (2020) relatam que sozinho, o teste possui baixa sensibilidade e por isso ter a possibilidade de liberar muitos falsos-positivos, principalmente em pacientes que se contaminaram recentemente, já que é necessário um tempo para que o sistema imunológico secrete imunoglobulinas (Ai et al., 2020).

\subsubsection{Quimioluminescência}

Há certas ocasiões em que o diagnóstico da COVID-19 pode se tornar difícil, principalmente em paciente assintomáticos, o que pode aumentar as incertezas quanto ao diagnóstico. Sabe-se que o exame mais confiável é o RT-PCR e que as análises laboratoriais têm um papel fundamental para o raciocínio diagnóstico. Porém, outras ferramentas adicionais podem auxiliar na avaliação e gerenciamento da doença, como por exemplo, a medição de anticorpos específicos para o SARS-CoV-2 (Padoan et al., 2020).

A baixa carga viral, vista principalmente em fases assintomáticas, dificulta a detecção do vírus pela RT-PCR e pelos testes imunocromatográficos. Entretanto, a avaliação de anticorpos IgG e IgM com métodos mais sensíveis pode facilitar a confirmação da doença (Jin et al., 2020; Padoan et al., 2020).

No estudo de Padoan et al. (2020), foi verificado a cinética de IgM e IgG em 87 amostras de pacientes que se encontravam em enfermarias hospitalares. Todos os pacientes testaram positivo para a COVID-19 e a verificação foi confirmada pela técnica de RT-PCR em amostras de swab nasofaringe. Os pesquisadores avaliaram a cinética de $\operatorname{IgM}$ e $\operatorname{IgG}$ durante o início da fase febril observando a persistência dos anticorpos durante sete dias para IgM e doze para IgG através do método de imunoensaio de quimioluminescência. $\mathrm{O}$ estudo demonstra linearidade na detecção de anticorpos em concentrações de $1,5 \mathrm{UA} / \mathrm{mL}$ a $0,5 \mathrm{UA} / \mathrm{mL}$, havendo uma preservação da concentração de anticorpos séricos mesmo após diluições. A metodologia apresenta reprodutibilidade de $88 \%$ para IgM e $100 \%$ para IgG após o décimo terceiro dia de apresenta dos sintomas. Esses dados corrobora a utilização dessa técnica no diagnóstico e acompanhamento do paciente.

Na pesquisa de Cai et al. (2020), foi desenvolvido um imunoensaio quimioluminescente com o auxílio de peptídeos, atuando como imunossorventes para a deteç̧ão dos anticorpos específicos. As imunoglobulinas IgG e IgM apresentaram taxa de positividade de 71,4\% e 57,2\%, respectivamente. A combinação do imunoensaio desenvolvido com a RT-PCR em tempo real, revelou uma melhor precisão para o diagnóstico da COVID-19. A IgM não foi detectada antes da IgG, e esta última foi observado 2 dias após o início de febre. Em outros estudos também foi observado que a IgG foi detectada antes da IgM. (Jin et al., 2020; Lippi, et al., 2020b).

Apesar da RT-PCR ser usada para o diagnóstico etiológico da COVID-19, a detecção da resposta imune diante do vírus, notada pela presença de IgM ou IgG, corrobora para a vigilância epidemiológica. Em complemento, o advento da quimioluminescência tem um papel fundamental para o gerenciamento da doença, durante a manifestação dos sintomas (Lippi, et al., 2020a). 


\subsection{Alterações laboratoriais}

\subsubsection{Hemograma e Hemostasia}

O hemograma é o exame laboratorial mais solicitado no dia a dia clínico, pois permite a avaliar dos principais componentes celulares do sangue periférico. Desta forma, fornece informações acerca das alterações hematológicas para o diagnóstico de determinada patologia (Barros et al., 2016).

Não sendo diferente com a COVID-19, o hemograma também tem sido utilizado como exame de triagem para avaliar o estado clínico dos pacientes portadores de SARS-CoV-2 (Lescure et al., 2020). Segundo os estudo de L Chen et al. (2020), não há evidências em relação a alteração na quantidade de hemoglobina, contagem de hemácias e alteração significativa dos leucócitos totais, todavia, em relação ao leucograma, seus estudos coincidem com os de Qilin Li et al. (2020) quando citam que a maioria dos pacientes infectados apresentaram quadro de linfocitopenia, sendo este achado uma característica de infecção viral.

Em relação às plaquetas, os estudos de Huang et al. (2020) e Liu et al. (2020) demonstram que há uma diminuição significativa deste elemento figurado, como também encontraram anormalidades na contagem de eosinófilos que diminuíram nos pacientes infectados.

Observando os quadros de coagulopatia, Lippi, Plebani e Henry (2020) observaram que os pacientes mais graves, eram os que possuíam uma quantidade baixa de plaquetas justamente pela formação de trombos. Eles ainda concluem que a contagem de plaquetas pode diferenciar pacientes graves e não graves como também evidenciam que a quantidade delas é menor em pacientes que não sobreviveram à doença.

Alterações fibrinolíticas podem estar relacionadas com o aumento do dímero D. Pacientes positivo para SARS-CoV-2 que demonstraram quadros graves, principalmente devido a pneumonia, apresentaram níveis elevados de dímero D. Sendo assim, o aumento do dímero D é um marcador do estado de hipercoagulação sanguínea (Zhang et al., 2020).

\subsubsection{Bioquímica}

O SARS-CoV-2 pode causar danos através do processo inflamatório exacerbado devido a fisiopatologia da doença estar relacionada com a distribuição de receptores da ACE2 (Enzima Conversora da Angiotensina 2) nas células do organismo humano (Su et al., 2020). Sendo assim, o vírus não se limita a lesões apenas no trato respiratório onde há grande quantidade destes receptores. O vírus pode ocasionar danos em outros órgãos e sistemas, tornando o quadro ainda mais grave. Por isso, os parâmetros laboratoriais, especialmente os marcadores de função orgânica e marcadores imunológicos são importantes para monitorar a gravidade da doença (Su et al., 2020; Zhang et al., 2020).

A avaliação da função hepática é monitorada por meio da atividade da alanina aminotransferase (ALT) e da aspartato aminotrasferase (AST). No estudo de Zhang et al., (2020), essas enzimas foram empregadas para avaliar a função hepática, visto que alguns pacientes com COVID-19, apresentavam outras lesões. No entanto, foi explicado que outras causas poderiam estar envolvidas com as lesões hepáticas. Porém, outro estudo relatou níveis aumentados de ALT e AST em pacientes COVID19, principalmente em casos graves, e pacientes que tinham outras comorbidades (L. Chen et al., 2020). Os pesquisadores avaliaram a função renal com o uso da creatinina. Entretanto, alguns relataram que não houve diferenças significativas entre os pacientes (Zhang et al., 2020), já outros reportaram níveis normais ou diminuídos de ureia e creatinina, em pacientes com a COVID-19. No entanto, notou-se que em pacientes com casos mais leves os níveis de creatinina estariam aumentados, juntamente com a contagem de linfócitos (Chen et al., 2020).

Outros parâmetros como $\alpha$-hidroxibutirato desidrogenase, lactato desidrogenase (LDH) e a creatina quinase (CK), foram empregados para avaliar o miocárdio em pacientes com a COVID-19. Contudo, apesar dessas enzimas apresentarem níveis altos em pacientes com a COVID-19, se faz necessário evidências radiológicas e histológicas para comprovar a 
ocorrência de danos ao miocárdico (Zhang et al., 2020). Foi observado que além dessas enzimas, foi reportado o aumento de creatina quinase-MB (CK-MB) em crianças e adultos, sugerindo possíveis danos ao músculo cardíaco (Su et al., 2020). Também foi relatado níveis aumentados de lactato desidrogenase (LDH) em alguns pacientes COVID-19 positivo e pacientes que apresentavam outras patologias. Nos quadros mais graves, o aumento da LDH é mais significativo, quando comparado aos casos leves (Zhang et al., 2020). A diminuição da LDH e da CK foram observadas em pacientes que estavam em recuperação e receberam alta. Portanto, a carga viral estaria sendo eliminada e, consequentemente as enzimas estavam em menor quantidade (Yu et al., 2020).

Em conjunto com os biomarcadores acionados em resposta a infecção, como a proteína C reativa (PCR), procalcitonina (PCT) e a ferritina, as concentrações de IL-2R, IL-6, IL-8, IL-10 e TNF- $\alpha$, se elevaram com o aumento da gravidade da doença. Sendo assim, a magnitude da resposta exacerbada de citocinas pode condicionar os pacientes a quadros graves da COVID-19, resultando em uma alta morbimortalidade. A liberação da IL-2R na corrente sanguínea em resposta a ativação do sistema imune junto a linfopenia, podem se tornar biomarcadores em fases precoces de pacientes com quadros graves, além de serem importantes para a previsão da progressão da COVID-19 (Hou et al., 2020).

Os níveis de procalcitonina elevados estão relacionados a infecção, principalmente infecções de origem bacteriana. Entretanto em infecções virais pode ser observado um ligeiro aumento ou níveis baixos da substância. O estudo de X. Chen et al. (2020), avaliou a diferença dos níveis de procalcitonina em pacientes COVID-19 e pacientes que apresentavam outras comorbidades. Foi observado que a procalcitonina estava em níveis mais altos em pacientes que apresentaram outras patologias. Desta forma, a procalcitonina elevada pode indicar a possível etiologia das comorbidades desses pacientes. Outra comparação com os casos leves e graves da COVID-19, relatou que a procalcitonina estava significativamente mais elevada em pacientes que apresentaram quadros mais graves (Chen et al., 2020).

A proteína $\mathrm{C}$ reativa também foi observada em níveis médios em pacientes que apresentaram outras patologias, em comparação com pacientes COVID-19 positivo. No entanto as porcentagens de ambos os pacientes com níveis elevados não foram significativamente diferentes. Em pacientes COVID-19 com quadros mais graves a proteína C reativa estava em níveis mais elevados (Chen et al., 2020). Em adição, a inflamação exacerbada foi observada em pacientes que apresentavam pneumonia pelo SARS-CoV-2, curiosamente, os níveis de proteína C reativa estavam aumentados (Huang et al., 2020; G. Zhang et al., 2020). O aumento da proteína C reativa acompanha os estágios iniciais da doença e quando esse parâmetro está associado a liberação de citocinas, pode indicar a estágios mais graves da doença (Qilin Li et al., 2020).

\section{Conclusão}

A atual realidade tem nos mostrado a grande relevância dos exames laboratoriais. Além disso, essas ferramentas de diagnóstico têm sido cruciais para o acompanhamento do paciente com sintomas da COVID, servindo de apoio aos médicos para a tomada de decisões no que se refere à prevenção, diagnóstico, tratamento e prognóstico de um indivíduo acometido pelo SARS-CoV-2. Esta revisão demonstra que existem diferentes metodologias para a detecção do vírus bem como alterações em exames laboratoriais que evidencia o estado clínico do indivíduo com a COVID-19. Dessa forma, o investimento em ferramentas de diagnóstico se faz necessário na tentativa de buscar melhorias e métodos mais eficazes, mais rápidos, com maior sensibilidade e especificidade minimizando os erros pré-analíticos, analíticos e pós analíticos. Consequentemente, trazendo resultados com maior acurácia e redução de resultados falsos positivos e falsos negativos que irão beneficiar mais ainda a população em geral.

Vale ressaltar que por se tratar de uma revisão da literatura, não podemos extrapolar os resultados apresentados nesse recorte temporal para todas as metodologias disponíveis no mercado, já que estas podem possuir limitações inerentes às tecnologias utilizadas no desenvolvimento dos kits reagentes e às variações analíticas que estão associadas ao treinamento e 
experiência do analista clínico. Por isso, se faz necessário estudos mais robustos para avaliar o desenvolvimento de diversas técnicas, suas performances e possíveis interferentes analíticos.

\section{Referências}

Ai, T., Yang, Z., Hou, H., Zhan, C., Chen, C., Lv, W., Tao, Q., Sun, Z., \& Xia, L. (2020). Correlation of Chest CT and RT-PCR Testing for Coronavirus Disease 2019 (COVID-19) in China: A Report of 1014 Cases. Radiology, 296(2), E32-E40. https://doi.org/10.1148/radiol.2020200642

Andersen, K. G., Rambaut, A., Lipkin, W. I., Holmes, E. C., \& Garry, R. F. (2020). The proximal origin of SARS-CoV-2. Nature Medicine, $26(4)$, 450-452. https://doi.org/10.1038/s41591-020-0820-9

Barros, E., Xavier, R. M., \& Dora, J. M. (2016). Laboratório na prática clínica: consulta rápida (3a ed.). ARTMED.

Brasil. (2020). Doença pelo coronavírus 2019. Especial Vigilância Epidemiológica Laboratorial. Boletim Epidemiológico. In Ministério da Saúde. https://portalarquivos.saude.gov.br/images/pdf/2020/April/19/BE12-Boletim-do-COE.pdf

Cai, X., Chen, J., Hu, J., Long, Q., Deng, H., Fan, K., Liao, P., Liu, B., Wu, G., Chen, Y., Li, Z., Wang, K., Zhang, X., Tian, W., Xiang, J., Du, H., Wang, J., Hu, Y., Tang, N., ... Wang, D. (2020). A Peptide-based Magnetic Chemiluminescence Enzyme Immunoassay for Serological Diagnosis of Corona Virus Disease 2019 (COVID-19). MedRxiv. https://doi.org/10.1101/2020.02.22.20026617

Chan, J. F. W., Yip, C. C. Y., To, K. K. W., Tang, T. H. C., Wong, S. C. Y., Leung, K. H., Fung, A. Y. F., Ng, A. C. K., Zou, Z., Tsoi, H. W., Choi, G. K. Y., Tam, A. R., Cheng, V. C. C., Chan, K. H., Tsan, O. T. Y., \& Yuen, K. Y. (2020). Improved molecular diagnosis of COVID-19 by the novel, highly sensitive and specific COVID-19-RdRp/Hel real-time reverse transcription-PCR assay validated in vitro and with clinical specimens. Journal of Clinical Microbiology, 58(5). https://doi.org/10.1128/JCM.00310-20

Chen, L., Liu, H. G., Liu, W., Liu, J., Liu, K., Shang, J., Deng, Y., \& Wei, S. (2020). Analysis of clinical features of 29 patients with 2019 novel coronavirus pneumonia. Zhonghua jie he he hu xi za zhi = Zhonghua jiehe he huxi zazhi = Chinese journal of tuberculosis and respiratory diseases, 43(0), E005. https://doi.org/10.3760/cma.j.issn.1001-0939.2020.0005

Chen, X., Yang, Y., Huang, M., Liu, L., Zhang, X., Xu, J., Geng, S., Han, B., Xiao, J., \& Wan, Y. (2020). Differences between COVID-19 and suspected then confirmed SARS-CoV-2-negative pneumonia: A retrospective study from a single center. Journal of Medical Virology, 92(9), 1572-1579. https://doi.org/10.1002/jmv.25810

Colantuoni, A., Martini, R., Caprari, P., Ballestri, M., Capecchi, P. L., Gnasso, A., Lo Presti, R., Marcoccia, A., Rossi, M., \& Caimi, G. (2020). COVID-19 Sepsis and Microcirculation Dysfunction. Frontiers in Physiology, 11(June), 1-6. https://doi.org/10.3389/fphys.2020.00747

Corman, V. M., Landt, O., Kaiser, M., Molenkamp, R., Meijer, A., Chu, D. K. W., Bleicker, T., Brünink, S., Schneider, J., Schmidt, M. L., Mulders, D. G. J. C., Haagmans, B. L., Van Der Veer, B., Van Den Brink, S., Wijsman, L., Goderski, G., Romette, J. L., Ellis, J., Zambon, M., \& Drosten, C. (2020). Detection of 2019 novel coronavirus (2019-nCoV) by real-time RT-PCR. Eurosurveillance, 25(3), 1-8. https://doi.org/10.2807/1560-7917.ES.2020.25.3.2000045

Decaro, N., \& Lorusso, A. (2020). Novel human coronavirus (SARS-CoV-2): A lesson from animal coronaviruses. Veterinary Microbiology, 244(April), 108693. https://doi.org/10.1016/j.vetmic.2020.108693

Demey, B., Daher, N., François, C., \& Lanoix, J. (2020). Dynamic profile for the detection of anti-SARS-CoV-2 antibodies using four immunochromatographic assays Baptiste. Journal of Infection, 81. https://dx.doi.org/10.1016\%2Fj.jinf.2020.04.033

Gallagher, T. M., \& Buchmeier, M. J. (2001). Coronavirus spike proteins in viral entry and pathogenesis. Virology, 279(2), 371-374. https://doi.org/10.1006/viro.2000.0757

Gorbalenya, A. E., Baker, S. C., Baric, R. S., de Groot, R. J., Drosten, C., Gulyaeva, A. A., Haagmans, B. L., Lauber, C., Leontovich, A. M., Neuman, B. W., Penzar, D., Perlman, S., Poon, L. L. M., Samborskiy, D. V., Sidorov, I. A., Sola, I., \& Ziebuhr, J. (2020). The species Severe acute respiratory syndromerelated coronavirus: classifying 2019-nCoV and naming it SARS-CoV-2. Nature Microbiology, 5(4), 536-544. https://doi.org/10.1038/s41564-020-0695-Z

Guan, W., Ni, Z., Hu, Y., Liang, W., Ou, C., He, J., Liu, L., Shan, H., Lei, C., Hui, D. S. C., Du, B., Li, L., Zeng, G., Yuen, K. Y., Chen, R., Tang, C., Wang, T., Chen, P., Xiang, J., ... Zhong, N. (2020). Clinical characteristics of coronavirus disease 2019 in China. New England Journal of Medicine, 382(18), 17081720. https://doi.org/10.1056/NEJMoa2002032

Hoffmann, M., Kleine-Weber, H., Krüger, N., Müller, M., Drosten, C., \& Pöhlmann, S. (2020). The novel coronavirus 2019 (2019-nCoV) uses the SARScoronavirus receptor ACE2 and the cellular protease TMPRSS2 for entry into target cells. SCIENCE, 367(6485), 1444-1448. https://doi.org/10.1101/2020.01.31.929042

Hou, H., Zhang, B., Huang, H., Luo, Y., Wu, S., Tang, G., Liu, W., Mao, L., Mao, L., Wang, F., \& Sun, Z. (2020). Using IL-2R/lymphocytes for predicting the clinical progression of patients with COVID-19. Clinical and Experimental Immunology, 201(1), 76-84. https://doi.org/10.1111/cei.13450

Huang, C., Wang, Y., Li, X., Ren, L., Zhao, J., Hu, Y., Zhang, L., Fan, G., Xu, J., \& Gu, X. (2020). Clinical features of patients infected with 2019 novel coronavirus in Wuhan, China. The Lancet, 395(10223), 497-506. https://doi.org/10.1016/S0140-6736(20)30183-5

Huang, Q., Deng, X., Li, Y., Sun, X., Chen, Q., Xie, M., Liu, S., Qu, H., Liu, S., Wang, L., He, G., \& Gong, Z. (2020). Clinical characteristics and drug therapies in patients with the common-type coronavirus disease 2019 in Hunan, China. International Journal of Clinical Pharmacy, 42(3), 837-845. https://doi.org/10.1007/s11096-020-01031-2

Imai, K., Tabata, S., Ikeda, M., Noguchi, S., Kitagawa, Y., Matuoka, M., Miyoshi, K., Tarumoto, N., Sakai, J., Ito, T., Maesaki, S., Tamura, K., \& Maeda, T. (2020). Clinical evaluation of an immunochromatographic IgM/IgG antibody assay and chest computed tomography for the diagnosis of COVID-19. Journal of Clinical Virology, 128(April), 104393. https://doi.org/10.1016/j.jcv.2020.104393 
Jin, Y., Wang, M., Zuo, Z., Fan, C., Ye, F., \& Cai, Z. (2020). Diagnostic value and dynamic variance of serum antibody in coronavirus disease 2019. International Journal of Infectious Diseases, 94(0), 49-52. https://doi.org/10.1016/j.ijid.2020.03.065

Kim, J. Y., Ko, J. H., Kim, Y., Kim, Y. J., Kim, J. M., Chung, Y. S., Kim, H. M., Han, M. G., Kim, S. Y., \& Chin, B. S. (2020). Viral load kinetics of SARSCoV-2 infection in first two patients in Korea. Journal of Korean Medical Science, 35(7), 1-7. https://doi.org/10.3346/jkms.2020.35.e86

Lescure, F. X., Bouadma, L., Nguyen, D., Parisey, M., Wicky, P. H., Behillil, S., Gaymard, A., Bouscambert-Duchamp, M., Donati, F., Le Hingrat, Q., Enouf, V., Houhou-Fidouh, N., Valette, M., Mailles, A., Lucet, J. C., Mentre, F., Duval, X., Descamps, D., Malvy, D., \& Yazdanpanah, Y. (2020). Clinical and virological data of the first cases of COVID-19 in Europe: a case series. The Lancet Infectious Diseases, 20(6), 697-706. https://doi.org/10.1016/S14733099(20)30200-0

Li, Qilin, Ding, X., Xia, G., Chen, H. G., Chen, F., Geng, Z., Xu, L., Lei, S., Pan, A., Wang, L., \& Wang, Z. (2020a). Eosinopenia and elevated C-reactive protein facilitate triage of COVID-19 patients in fever clinic: A retrospective case-control study. EClinicalMedicine, 23, 100375. https://doi.org/10.1016/j.eclinm.2020.100375

Li, Qun, Guan, X., Wu, P., Wang, X., Zhou, L., Tong, Y., Ren, R., Leung, K. S. M., Lau, E. H. Y., Wong, J. Y., Xing, X., Xiang, N., Wu, Y., Li, C., Chen, Q., Li, D., Liu, T., Zhao, J., Liu, M., ... Feng, Z. (2020b). Early Transmission Dynamics in Wuhan, China, of Novel Coronavirus-Infected Pneumonia. New England Journal of Medicine, 382(13), 1199-1207. https://doi.org/10.1056/NEJMoa2001316

Li, Y., Yao, L., Li, J., Chen, L., Song, Y., Cai, Z., \& Yang, C. (2020). Stability issues of RT-PCR testing of SARS-CoV-2 for hospitalized patients clinically diagnosed with COVID-19. Journal of Medical Virology, 92(7), 903-908. https://doi.org/10.1002/jmv.25786

Lin, C., Lin, C., Xiang, J., Yan, M., Li, H., Huang, S., Huang, S., Shen, C., \& Shen, C. (2020). Comparison of throat swabs and sputum specimens for viral nucleic acid detection in 52 cases of novel coronavirus (SARS-Cov-2)-infected pneumonia (COVID-19). Clinical Chemistry and Laboratory Medicine, 58(7), 1089-1094. https://doi.org/10.1515/cclm-2020-0187

Ling, Y., Xu, S. B., Lin, Y. X., Tian, D., Zhu, Z. Q., Dai, F. H., Wu, F., Song, Z. G., Huang, W., Chen, J., Hu, B. J., Wang, S., Mao, E. Q., Zhu, L., Zhang, W. H., \& Lu, H. Z. (2020). Persistence and clearance of viral RNA in 2019 novel coronavirus disease rehabilitation patients. Chinese Medical Journal, 133(9), 1039-1043. https://doi.org/10.1097/CM9.0000000000000774

Lippi, G., \& Plebani, M. (2020). Laboratory abnormalities in patients with COVID-2019 infection. Clinical Chemistry and Laboratory Medicine, 58(7), 11311134. https://doi.org/10.1515/cclm-2020-0198

Lippi, G., Plebani, M., \& Henry, B. M. (2020). Thrombocytopenia is associated with severe coronavirus disease 2019 (COVID-19) infections: A metaanalysis. Clinica Chimica Acta, 506(March), 145-148. https://doi.org/10.1016/j.cca.2020.03.022

Lippi, G., Salvagno, G. L., Pegoraro, M., Militello, V., Caloi, C., Peretti, A., Gaino, S., Bassi, A., Bovo, C., \& Lo Cascio, G. (2020). Assessment of immune response to SARS-CoV-2 with fully automated MAGLUMI 2019-nCoV IgG and IgM chemiluminescence immunoassays. Clinical Chemistry and Laboratory Medicine, 58(7), 1156-1159. https://doi.org/10.1515/cclm-2020-0473

Liu, K., Fang, Y. Y., Deng, Y., Liu, W., Wang, M. F., Ma, J. P., Xiao, W., Wang, Y. N., Zhong, M. H., Li, C. H., Li, G. C., \& Liu, H. G. (2020). Clinical characteristics of novel coronavirus cases in tertiary hospitals in Hubei Province. Chinese Medical Journal, 133(9), 1025-1031 https://doi.org/10.1097/CM9.0000000000000744

Liu, R., Han, H., Liu, F., Lv, Z., Wu, K., Liu, Y., \& Feng, Y. (2020). Positive rate of RT-PCR detection of SARS-CoV-2 infection in 4880 cases from one hospital in Wuhan, China, from Jan to Feb 2020. Clinica Chimica Acta, 505(January). https://doi.org/10.1016/j.cca.2020.03.009

Padoan, A., Padoan, A., Cosma, C., Sciacovelli, L., Faggian, D., Plebani, M., \& Plebani, M. (2020). Analytical performances of a chemiluminescence immunoassay for SARS-CoV-2 IgM/IgG and antibody kinetics. Clinical Chemistry and Laboratory Medicine, 58(7), $1081-1088$. https://doi.org/10.1515/cclm-2020-0443

Pan, Y., Li, X., Yang, G., Fan, J., Tang, Y., Zhao, J., Long, X., Guo, S., Zhao, Z., Liu, Y., Hu, H., Xue, H., \& Li, Y. (2020). Serological immunochromatographic approach in diagnosis with SARS-CoV-2 infected COVID-19 patients. Journal of Infection, 81(1), e28-e32. https://doi.org/10.1016/j.jinf.2020.03.051

Paoli, D., Pallotti, F., Colangelo, S., Basilico, F., Mazzuti, L., Turriziani, O., Antonelli, G., Lenzi, A., \& Lombardo, F. (2020). Study of SARS-CoV-2 in semen and urine samples of a volunteer with positive naso-pharyngeal swab. Journal of Endocrinological Investigation, 0123456789, 1-4. https://doi.org/10.1007/s40618-020-01261-1

Peng, L., Liu, J., Xu, W., Luo, Q., Chen, D., Lei, Z., Huang, Z., Li, X., Deng, K., Lin, B., \& Gao, Z. (2020). SARS-CoV-2 can be detected in urine, blood, anal swabs, and oropharyngeal swabs specimens. Journal of Medical Virology, 92(9), 1676-1680. https://doi.org/10.1002/jmv.25936

Shen, B., Zheng, Y., Zhang, X., Zhang, W., Wang, D., Jin, J., Lin, R., Zhang, Y., Zhu, G., Zhu, H., Li, J., Xu, J., Ding, X., Chen, S., Lu, R., He, Z., Zhao, H., Ying, L., Zhang, C., ... Gao, H. (2020). Clinical evaluation of a rapid colloidal gold immunochromatography assay for SARS-Cov-2 IgM/IgG. American Journal of Translational Research, 12(4), 1348-1354. https://www.ncbi.nlm.nih.gov/pmc/articles/PMC7191168/

Su, L., Ma, X., Yu, H., Zhang, Z., Bian, P., Han, Y., Sun, J., Liu, Y., Yang, C., Geng, J., Zhang, Z., \& Gai, Z. (2020). The different clinical characteristics of corona virus disease cases between children and their families in China-the character of children with COVID-19. Emerging Microbes and Infections, 9(1), 707-713. https://doi.org/10.1080/22221751.2020.1744483

Sui-Lee, W., Donald G., M. J., \& Javier C., H. (2020). W.H.O. Declares Global Emergency as Wuhan Coronavirus Spreads. The New York Times. https://www.who.int/dg/speeches/detail/who-director-general-s-opening-remarks-at-the-media-briefing-on-covid-19---29-june-2020

Tortora, G. J., Funke, B. R., \& Case, C. L. (2016). Mcrobiologia. Artmed (12a ed.)

Wang, W., Xu, Y., Gao, R., Lu, R., Han, K., Wu, G., \& Tan, W. (2020). Detection of SARS-CoV-2 in Different Types of Clinical Specimens. JAMA - Journal 
of the American Medical Association, 323(18), 1843-1844. https://doi.org/10.1001/jama.2020.3786

Wang, X., Tan, L., Wang, X., Liu, W., Lu, Y., Cheng, L., \& Sun, Z. (2020). Comparison of nasopharyngeal and oropharyngeal swabs for SARS-CoV-2 detection in 353 patients received tests with both specimens simultaneously. International Journal of Infectious Diseases, 94, 107-109. https://doi.org/10.1016/j.ijid.2020.04.023

Wishaupt, J. O., Ploeg, T. Van Der, Smeets, L. C., \& Groot, R. De. (2020). Pitfalls in interpretation of CT-values of RT-PCR in children with acute respiratory tract infections. Journal of Clinical Virology, 90(January), 1-6. https://doi.org/10.1016/j.jcv.2017.02.010

World Health Organization. (2020). Novel Coronavirus(2019-nCoV). WHO Bulletin, February, 1-7. https://www.who.int/docs/defaultsource/coronaviruse/situation-reports/20200211-sitrep-22-ncov.pdf?sfvrsn=fb6d49b1_2

Wu, F., Zhao, S., Yu, B., Chen, Y. M., Wang, W., Song, Z. G., Hu, Y., Tao, Z. W., Tian, J. H., Pei, Y. Y., Yuan, M. L., Zhang, Y. L., Dai, F. H., Liu, Y., Wang, Q. M., Zheng, J. J., Xu, L., Holmes, E. C., \& Zhang, Y. Z. (2020). A new coronavirus associated with human respiratory disease in China. Nature, 579(7798), 265-269. https://doi.org/10.1038/s41586-020-2008-3

Wu, L., O'Kane, A. M., Peng, H., Bi, Y., Motriuk-Smith, D., \& Ren, J. (2020). SARS-CoV-2 and cardiovascular complications: From molecular mechanisms to pharmaceutical management. Biochemical Pharmacology, 178(June), 114114. https://doi.org/10.1016/j.bcp.2020.114114

Wu, Y., Guo, C., Tang, L., Hong, Z., Zhou, J., Dong, X., Yin, H., Xiao, Q., Tang, Y., Qu, X., Kuang, L., Fang, X., Mishra, N., Lu, J., Shan, H., Jiang, G., \& Huang, X. (2020). Prolonged presence of SARS-CoV-2 viral RNA in faecal samples. The Lancet Gastroenterology and Hepatology, 5(5), 434-435. https://doi.org/10.1016/S2468-1253(20)30083-2

Younes, N., Al-SAdeq, D. W., Al-Jighefee, H., Younes, S., Al-Jamal, O., Daas, H. I., Yassine, H. m., \& Nasrallah, G. K. (2020). Challenges in Laboratory Diagnosis of the Novel. Viruses, 12(6), 582. https://dx.doi.org/10.3390\%2Fv12060582

Yu, F., Yan, L., Wang, N., Yang, S., Wang, L., Tang, Y., Gao, G., Wang, S., Ma, C., Xie, R., Wang, F., Tan, C., Zhu, L., Guo, Y., \& Zhang, F. (2020). Quantitative Detection and Viral Load Analysis of SARS-CoV-2 in Infected Patients. Clinical Infectious Diseases : An Official Publication of the Infectious Diseases Society of America, 71(15), 793-798. https://doi.org/10.1093/cid/ciaa345

Zhang, C., Shi, L., \& Wang, F. S. (2020). Liver injury in COVID-19: management and challenges. The Lancet Gastroenterology and Hepatology, 5(5), 428430. https://doi.org/10.1016/S2468-1253(20)30057-1

Zhang, G., Zhang, J., Wang, B., Zhu, X., Wang, Q., \& Qiu, S. (2020). Analysis of clinical characteristics and laboratory findings of 95 cases of 2019 novel coronavirus pneumonia in Wuhan, China: a retrospective analysis. Respiratory Research, 21, 1-10. https://doi.org/10.21203/rs.3.rs-17712/v1

Zhou, P., Yang, X. Lou, Wang, X. G., Hu, B., Zhang, L., Zhang, W., Si, H. R., Zhu, Y., Li, B., Huang, C. L., Chen, H. D., Chen, J., Luo, Y., Guo, H., Jiang, R. Di, Liu, M. Q., Chen, Y., Shen, X. R., Wang, X., \& Shi, Z. L. (2020). A pneumonia outbreak associated with a new coronavirus of probable bat origin. Nature, 579(7798), 270-273. https://doi.org/10.1038/s41586-020-2012-7

Zhu, N., Zhang, D., Wang, W., Li, X., Yang, B., Song, J., Zhao, X., Huang, B., Shi, W., Lu, R., Niu, P., Zhan, F., Ma, X., Wang, D., Xu, W., Wu, G., Gao, G. F., \& Tan, W. (2020). A Novel Coronavirus from Patients with Pneumonia in China, 2019. New England Journal of Medicine, 382(8), 727-733. https://doi.org/10.1056/NEJMoa2001017 